\title{
Cultural and psychological determinants of pain assessment during lower limb angioplasty
}

\author{
Michał-Goran Stanišić', Teresa Rzepa², Jarosław Nakonieczny³, Przemysław Kubaszewski², \\ Maciej Putowski ${ }^{4}$, Marta Popek ${ }^{2}$, Athanasios Liougkos ${ }^{3}$ \\ 'Department of Vascular and Endovascular Surgery, Angiology and Phlebology, Poznan University of Medical Sciences, Poland \\ ${ }^{2}$ University of Social Sciences and Humanities, Department of Poznan, Poland \\ ${ }^{3}$ Department of Vascular and Endovascular Surgery, GPR-Klinikum Rüsselsheim, Germany \\ ${ }^{4}$ Medical University of Lublin, Poland
}

\begin{abstract}
Introduction. It is a common unofficial perception of surgeons performing endovascular operations that patients living in the different social and economic environment assess pain differently during peripheral angioplasty procedures.

The objective was to examine the differences in assessing pain experienced during endovascular arterial interventions on lower limbs, by Polish and German patients, and to analyse the psychological determinants of the assumed differences, by referring to mental dispositions such as optimism and satisfaction with own life quality. Material and methods. 101 patients were qualified for endovascular intervention on lower limbs arteries - 51 Germans $(M=67.31$; SD = 9.82) and 50 Poles (age $M=67.88 ; S D=8.4$ ). 37 women and 64 men were classified as Rutherford category 2-3.

Three scales were applied:

1. Life Orientation Test-Revised

2. Satisfaction With Life Scale

3. Pain Appraisal Scale which comprises emoticons showing subsequent degrees of sustained pain and the corresponding Visual Analogue Scale.
\end{abstract}

Results. The patients from Poland graded their life quality lower than the German patients ( $M=23.44$; SD $=5.977$ and $M=25.94 ; S D=5.584)$. The Poles presented a lower level of optimism $(M=15.04 ; S D=$ 3.703 vs $M=15.8 ; S D=3.516$ ). The Polish patients classified the level of pain during lower limb angioplasty as higher than in German patients ( $M=4.22 ; S D=2.999$ and $M=2.88 ; S D=2.215)(p<0.012)$.

Conclusions. Resistance to pain experienced during endovascular procedures probably depends on the assessment of the patient's current life situation, determined by satisfaction with own life quality and related optimism. With great caution, it might also be supposed that resistance to pain depends on the life standard typical of a given population.

Key words: lower limb angioplasty, pain measurement, social determinants

Acta Angiol 2018; 24, I: 9-13

\section{Introduction}

Diminishing the invasiveness of peripheral vessels surgery leads to decreased post-operative pain and shortening the hospitalisation and post-hospital recovery time [I]. However, infiltration anaesthesia applied at the vascular access place during endovascular operations does not fully eliminate pain and discomfort ex- 
perienced by patients in the course of the intervention. During peripheral vessel angioplasty, patients complain about discomfort and pain connected with manipulations at the artery access point, pain connected with balloon inflation during angioplasty, pain and discomfort connected with the forced body position during the procedure that may last even several hours. Sedation also does not totally eliminate the feeling of endovascular manipulation during the operation [2].

Endovascular treatment is a standard in the case of peripheral arterial lesions in intermittent claudication patients without critical ischaemia of lower extremities, regardless of their advanced stage as per TASC classification [I, 3]. Choosing endovascular treatment as the first-choice method of intervention enables patients quick returning to work or, in the case of elderly patients, to unhindered everyday functioning $[I, 3]$. Although patients are warned about the possibility of feeling pain during an endovascular procedure, the patients' reactions sometimes lead to the need of sedation or broadening the scope of anaesthesia. At the same time, medical staff are very subjective in assessing the pain sustained by a patient. A surgeon may underestimate the level of pain felt by a patient in relation to the invasiveness of the procedure. Pain experienced by patients during peripheral angioplasty has not often been a subject of clinical analyses. Additionally, most publications are based on early reports regarding coronary angioplasty and dialysis access and early endovascular procedures performed on peripheral vessels $[1,4,5]$.

There is a number of stereotypes regarding pain experienced by patients during peripheral artery angioplasty. Such common opinions, not documented in the literature on vascular surgery and interventional radiology, regard age, gender and nationality of patients. It is a common perception of surgeons performing endovascular operations that patients living in Poland are testier during the operation and tend to feel pain earlier during angioplasty procedures, compared to patients living in Germany.

Peripheral vessel angioplasty in the femoropopliteal and iliofemoral areas is a standardised procedure in terms of the sequence of actions and applied operation techniques. There are international standards of preparing patients and attending them during endovascular operations [2, 6]. Additionally, in the case of angioplasty procedures performed due to intermittent claudication, we deal with patients who expect improvement of their life quality and who do not suffer from chronic ischaemic pain, which has an effect on pain perception during the operation.

Sociocultural and psychological studies on health behaviours and on coping with disease and pain have shown that people react differently to being ill and suffering. The underlying causes of the differences are both cultural factors (including the nationality) that affect the way people meet their health needs and psychological factors in the form of personal resources determining the behaviours connected with health and disease. A combination of those factors models individual ideas and stereotypes regarding health and disease, the way of experiencing and interpreting causes and symptoms of disease, attitudes to disease, pain, medical staff, patient's role, treatment procedures, prophylaxis and lifestyle [I-5]. The way of experiencing, expressing and controlling pain is one of the behaviours learned in the course of gaining individual experience and socialisation, depending on the kind of social environment, and therefore nationality. At the same time, coping with a disease and its consequences i.e. pain, mood disorders, bad mental condition etc. requires activation of personal resources [6, 7]. Among the resources, dispositional optimism is of particular importance, as it promotes resistance to stressful life events and positive assessment of one's life quality [8-II]. The studies conducted by Morris et al. [7], Rollman et al. [10] and Baum et al. [I I] have taken up cultural aspects of the perception of pain, however, their analysis did not focus on differences in specific types of surgical interventions.

With reference to those findings, the purpose of this paper is to examine the differences in assessing pain experienced during angioplasty of lower limb arteries in the femoropopliteal and iliofemoral areas by Polish and German patients, and to analyse the psychological determinants of the assumed differences by referring to mental dispositions such as optimism and satisfaction with own life quality.

\section{Material and methods}

After obtaining a consent from the Local Research Ethics Committee, IOI patients were qualified for angioplasty in the iliofemoral and femoropopliteal areas, including $5 \mathrm{I}$ Germans (mean age $M=67.3 \mathrm{I}$; $S D=9.82$ ) and 50 Poles (mean age $M=67.88$; $S D=8.4$ ). The group included 37 women and 64 men. The patients were classified as Rutherford category $2-3$, without rest pain or necrotic foci. Patients with diagnosed diabetic neuropathy were excluded from the study. All the patients gave their informed consent to participate in the research study.

In view of the study objective, 3 scales were applied, which were completed - with the help of the researchers - by the patients undergoing the elective surgery. The tests were:

I. The Life Orientation Test-Revised (LOT-R; developed by: M.F. Scheier, C.S. Carver, M.W. Bridges; 
Table I. Between-subjects factors tests: nationality and life quality assessment, optimism and sustained pain

\begin{tabular}{|c|c|c|c|c|c|}
\hline Fixed factor & Dependent variable & Type III sum of squares & $\mathbf{F}$ & Significance & $\begin{array}{c}\text { Partial eta-squared } \\
\text { values }\end{array}$ \\
\hline Nationality & Life quality assessment & 157.946 & 4.725 & .032 米 & .046 \\
\hline Nationality & Optimism level & 14.734 & 1.131 & .290 & .011 \\
\hline Nationality & Experienced pain level & 45.175 & 6.521 & $.012^{*}$ & .062 \\
\hline
\end{tabular}

*p $<0.05$

Table 2. Between-subjects factors tests: correlation between assessment of experienced pain, optimism and life quality assessment

\begin{tabular}{|l|l|c|c|c|c|}
\hline Fixed factor & Dependent variable & Type III sum of squares & F & Significance & $\begin{array}{l}\text { Partial eta-squared } \\
\text { values }\end{array}$ \\
\hline Life quality assessment & Optimism level & 139.265 & 5.855 & $.004 * *$ & .107 \\
\hline Life quality assessment & Experienced pain level & 71.608 & 5.321 & $.006 * *$ & .098 \\
\hline Optimism level & Life quality assessment & 238.662 & 3.622 & $.030 *$ & .069 \\
\hline Experienced pain level & Life quality assessment & 342.064 & 5.364 & $.006 * *$ & .099 \\
\hline
\end{tabular}

* $\mathrm{p}<0.05 ; * * \mathrm{p}<0.0$ I

Polish adaptation: Z. Juczyński), consisting of 10 statements and applied to measure dispositional optimism [12, 13].

2. Satisfaction With Life Scale (SWLS, by: E. Diener, R.A. Emmons, R.J. Larson, S. Griffin; Polish adaptation: Z. Juczyński), composed of 5 statements and measuring the generalised feeling of satisfaction with one's life [13, 14].

3. Pain Appraisal Scale which comprises both emoticons showing subsequent (from I to 6) degrees of sustained pain and the corresponding Visual Analogue Scale which enables evaluation of pain intensity from 0 (no pain) to 10 (maximum, unbearable pain) [15].

Scales I and 2 served to measure mental dispositions being part of personal resources (dispositional optimism and quality of own life), while scale 3 - to specify the intensity of pain experienced during lower limb angioplasty. Scale no. 3 was used after the surgical procedure.

The statistical analysis of the results was done by means of IBM SPSS Statistics 22 software. To assess the normality of distribution of the analysed variables, the Shapiro-Wilk test was applied and it showed that the results distribution was normal. Homogenity of variances in the compared groups was checked by means of Levene's test. In order to specify the strength of correlation between the variables, Pearson correlation coefficient ( $r$ ) was applied, and the principal effects and interactions between the variables were verified on the basis of variance analysis in the multivariable model.

\section{Results}

It was found that the Polish patients graded their life quality lower than the patients from Germany (respectively: $M=23.44$; $S D=5.977$ and $M=25.94$; $S D=$ 5.584). The Polish subjects were also characterised by a lower level of optimism compared to the Germans (respectively: $M=15.04 ; S D=3.703$ and $M=15.8$; $S D=3.516)$. Simultaneously, the Polish patients classified the level of pain experienced during lower limb angioplasty as higher than in the case of the German patients (respectively: $M=4.22 ; S D=2.999$ and $M=2.88 ; S D=2.215)$. The variance analysis showed that life quality assessment made by the patients from Poland was statistically significantly lower than the one made by their German counterparts ( $p<0.032$ ), and also the rating of pain experienced by the Polish patients was statistically significantly higher than in the case of the German patients ( $p<0.012$ ). However, both groups were not different in terms of optimism level $(p<0.290)$ (Table I).

Then, correlations between the variables were checked and it was found that regardless of nationality (Table 2):

I. The research study subjects who rated their life quality higher were characterised by a higher level of optimism ( $M=16.82$; $S D=3.478)$ than in the case of patients who graded their life quality lower $(M=14.14 ; S D=3.668)$. This correlation proved to be statistically significant ( $p<004)$.

2. The research study subjects who rated their life quality higher assessed the pain they sustained as weaker $(M=2.54 ; S D=2.327)$ than in the case of patients who graded their life quality lower $(M=4.46 ; S D=2.745)$. This correlation proved to be statistically significant $(p<006)$.

3. The patients showing a higher optimism level graded their life quality higher $(M=26.40 ; S D=5.912)$ than those with a lower optimism level $(M=22.7 \mathrm{I}$; $S D=4.939)$. This correlation proved to be statistically significant $(p<030)$.

4. The research study subjects who assessed their pain as greater, rated their life quality lower $(M=22.68$; 
Table 3. Correlations (Pearson correlation coefficient) between the level of experienced pain, optimism and life quality in patients from Germany and from Poland

\begin{tabular}{|c|c|c|c|c|}
\hline \multirow{2}{*}{ Variable } & \multicolumn{2}{|c|}{ German } & \multicolumn{2}{|c|}{ Poles } \\
\hline & Quality of life & Optimism & Quality of life & Optimism \\
\hline Optimism & $\begin{array}{c}.516^{*} * \\
.000\end{array}$ & $x$ & $\begin{array}{l}.067 \\
.646 \\
\end{array}$ & $X$ \\
\hline Pain assessment & $\begin{array}{r}-.154 \\
.280\end{array}$ & $\begin{array}{l}-.185 \\
.193\end{array}$ & $\begin{array}{c}-.385^{* * *} \\
.006\end{array}$ & $\begin{array}{r}-.039 \\
.786\end{array}$ \\
\hline
\end{tabular}

*** Correlation is significant at the 0.01 level (2-tailed)

$\mathrm{SD}=5.706)$ compared to those who graded their pain as smaller $(M=26,60 ; S D=5,603)$. This correlation proved to be statistically significant $(\mathrm{p}<006)$.

Moreover, correlations between the variables were checked in relation to both nationalities and it was found that in the case of German patients there was a strong positive correlation between own life quality assessment and optimism level $(p<0.000)$, and in the case of patients from Poland there was a strong negative correlation between the assessment of sustained pain and of own life quality $(p<0.006)$ (Table 3$)$.

\section{Discussion}

Endovascular procedures constitute a majority of currently performed operations in connection with intermittent claudication in lower extremities atherosclerosis. From the medical point of view, the perioperative pain management used so far seemed to be optimal. Following endovascular procedures, patients come back to normal life much faster and feel smaller postoperative pain compared to classical surgery. The astonishing population differences impose the need to consider the causes of different experiencing of pain in the individual patient groups.

Many studies indicate a relation between the evaluation of experienced pain and pessimism, depressive disorders, anxiety, low quality of life $[16,17]$, concurrently emphasising the significant role of optimism and high quality of life in coping even with chronic pain [18-20]. The results of this research study have confirmed this correlation both ways, as the patients who graded their life quality higher were characterised by a higher level of optimism and found the pain sustained during lower extremity angioplasty weaker. Meanwhile, patients who assessed their life quality lower showed a lower level of optimism and graded the pain sustained by them during the surgical procedure as significantly stronger.

Although the causes of differences in experiencing pain are often sought in the broadly understood cultural factors [2I-23], rarely were they connected with a particular nationality [24]. The results of this research study have shown significant differences in this regard between patients from Germany and Poland. It was established that the Polish patients evaluated their life quality significantly lower than the German ones who satisfied with their life quality - simultaneously showed a high level of optimism. In the context of confirming the significance of the personal resources in coping with pain, it is not surprising that the German patients assessed the pain sustained during lower extremity angioplasty as significantly smaller than in the case of the Polish patients.

\section{Conclusions}

The presented data lead to a conclusion that due to the Polish patients' increased sensitivity to pain, a change in the perioperative pain management should be considered, e.g. more frequent use of sedation or routine administration of intravenous analgesics to all patients undergoing angioplasty procedures. Changing the strategy and course of proceeding should be subject to further studies.

The resistance to pain experienced during surgical procedures probably depends on the assessment of the patient's current life situation, determined by satisfaction with own life quality and related optimism. The study has a number of limitations due to a specific group of patients and also to conducting in two centres with a similar standardised approach. With great caution, it might also be supposed that resistance to pain depends on the life standard typical of a given population.

\section{Conflict of interest}

None.

\section{References:}

I. Norgren L, Hiatt WR, Dormandy JA, et al. TASC II Working Group. Inter-Society Consensus for the Management of Peripheral Arterial Disease (TASC II). Eur J Vasc Endovasc Surg. 2007; 33 Suppl I: SI-75, doi: 10.1016/j.ejvs.2006.09.024, indexed in Pubmed: |7|40820.

2. Mueller PR, Biswal S, Halpern EF, et al. Interventional radiologic procedures: patient anxiety, perception of pain, understanding 
of procedure, and satisfaction with medication--a prospective study. Radiology. 2000; 215(3): 684-688, doi: 10.1 I48/radiology.215.3.r00jn33684, indexed in Pubmed: 10831684.

3. Katsanos K, Tepe G, Tsetis D, et al. Standards of practice for superficial femoral and popliteal artery angioplasty and stenting. Cardiovasc Intervent Radiol. 2014; 37(3): 592-603, doi: 10.1007/s00270-014-0876-3, indexed in Pubmed: 24722891.

4. Kee F, McDonald P, Gaffney B. Risks and benefits of coronary angioplasty: the patients perspective: a preliminary study. Qual Health Care. 1997; 6(3): |31-139, indexed in Pubmed: 10173770.

5. Haines WY, Deets R, Lu N, et al. Tumescent anesthesia reduces pain associated with balloon angioplasty of hemodialysis fistulas. J Vasc Surg. 2012; 56(5): |453-|456, doi: 10.1016/j. jvs.2012.05.094, indexed in Pubmed: 22885। 29.

6. Rossi M, lezzi R. Cardiovascular and Interventional Radiological Society of Europe guidelines on endovascular treatment in aortoiliac arterial disease. Cardiovasc Intervent Radiol. 20 14; 37(I): 13-25, doi: 10.1007/s00270-013-074I-9, indexed in Pubmed: 24196266.

7. Morris DB. The culture of pain. University of California Press, Berkeley 1991.

8. Linton SJ, Shaw WS. Impact of psychological factors in the experience of pain. Phys Ther. 201 I; 9I(5): 700-7II, doi: 10.2522/ ptj.20100330, indexed in Pubmed: 21451097.

9. Brihaye J, Loew F, Pia H. Pain: a medical and anthropological challenge. Springer-Verlag, New York 1987.

10. Rollman GB. Culture and pain. In: Kazarian SS, Ewans DR. ed. Cultural clinical psychology: Theory, research, and practice. Oxford University Press, New York 1998: 267-286.

II. Baum SK, Stewart RB. Sources of meaning through the lifespan. Psychol Rep. 1990; 67(I): 3-14, doi: 10.2466/pr0.1990.67.1.3, indexed in Pubmed: 22364I0.

12. Scheier MF, Carver CS, Bridges MW. Distinguishing optimism from neuroticism (and trait anxiety, self-mastery, and self-esteem): a reevaluation of the Life Orientation Test. J Pers Soc Psychol. 1994; 67(6): 1063-1078, indexed in Pubmed: 7815302.

13. Juczyński Z. Measurement tools in health promotion and health psychology. Psychological Test Lab of the Polish Psychological Association, Warsaw 200I.
14. Pavot W, Diener Ed. The Satisfaction With Life Scale and the emerging construct of life satisfaction. The Journal of Positive Psychology. 2008; 3(2): 137-152, doi: 10.1080/17439760701756946.

15. Gendreau M, Hufford M, Stone A. Measuring clinical pain in chronic widespread pain: selected methodological issues. Best Practice \& Research Clinical Rheumatology. 2003; 17(4): 575592, doi: $10.1016 / \mathrm{s}|52|-6942(03) 00031-7$.

16. Vlaeyen J, Linton S. Fear-avoidance and its consequences in chronic musculoskeletal pain: a state of the art. Pain. 2000; 85(3): 317-332, doi: 10.1016/s0304-3959(99)00242-0.

17. Wiech K, Tracey I. The influence of negative emotions on pain. Neurolmage. 2009; 47(987): 994.

18. Peterman AH, Cella D. Quality of life. In: Kazdin AE, Cella D. ed. Encyclopedia of psychology. Oxford University Press-American Psychological Association, Oxford 2000: 40I-495.

19. Kivimäki M, Vahtera J, Elovainio M, et al. Optimism and pessimism as predictors of change in health after death or onset of severe illness in family. Health Psychol. 2005; 24(4): 413-42I, doi: 10.1037/0278-6133.24.4.413, indexed in Pubmed: 16045377.

20. Fournier M, Ridder Dde, Bensing J. How optimism contributes to the adaptation of chronic illness. A prospective study into the enduring effects of optimism on adaptation moderated by the controllability of chronic illness. Personality and Individual Differences. 2002; 33(7): II63-II83, doi: 10.1016/s01918869(02)00006-5.

21. Callister L. Cultural Influences on Pain Perceptions and Behaviors. Home Health Care Management \& Practice. 2016; 15(3): 207-2 II, doi: 10.1 I77/1084822302250687.

22. Stanisić M, Rzepa T. Attitude towards one's illness vs. attitude towards a surgical operation, displayed by patients diagnosed with asymptomatic abdominal aortic aneurysm and asymptomatic internal carotid artery stenosis. Int Angiol. 2012; 31(4): 376-385, indexed in Pubmed: $2280 I 404$.

23. Janowski K, Steuden S. Biopsychosocial aspects of health and disease. CPPP Scientific Press, Lublin 2009.

24. Edwards RR, Doleys DM, Fillingim RB, et al. Ethnic differences in pain tolerance: clinical implications in a chronic pain population. Psychosom Med. 200I; 63(2): 316-323, indexed in Pubmed: II29228I. 